\title{
Subarachnoid Hemorrhage from Vertebral Arteriovenous Fistula without Perimedullary Drainage: Rare Stroke Hemorrhagic Event in a Patient of Neurofibromatosis Type 1
}

\author{
Yoshinori MAKI, ${ }^{1}$ Ryota ISHIBASHI, ${ }^{1}$ Hitoshi FUKUDA, ${ }^{1}$ Miyako KOBAYASHI, ${ }^{1}$ \\ Masaki CHIN, ${ }^{1}$ and Sen YAMAGATA ${ }^{1}$
}

${ }^{1}$ Department of Neurosurgery, Kurashiki Central Hospital, Kurashiki, Okayama, Japan

\begin{abstract}
Vertebral arteriovenous fistula (VAVF), which can cause subarachnoid hemorrhage (SAH) when having a perimedurally drainage, has been reported as a rare vascular abnormality in patients with neurofibromatosis type 1 (NF-1). In addition, extracranial vertebral aneurysm (EVAn) coexisting with VAVF and NF-1 is considered rare, and further complication with SAH is extremely rare in patients. There is only one reported case of NF-1 complicated with SAH from VAVF with an EVAn. Here, we present a case of a middle-aged patient with NF-1. The VAVF accompanied by an EVAn was detected with an episode of SAH. The VAVF with an EVAn in our case was accompanied with an epidural varix, lacking of perimedullary drainage, which could be a cause for SAH. We speculate the mechanism of SAH from the VAVF with an EVAn lacking of perimedurally drainage, focusing on hemodynamic stress of the VAVF and the tissue fragility related to NF-1.
\end{abstract}

Key words: vertebral arteriovenous fistula, vertebral aneurysm, neurofibromatosis type 1, subarachnoid hemorrhage, endovascular treatment

\section{Introduction}

Vertebral arteriovenous fistula (VAVF), which can cause subarachnoid hemorrhage (SAH) when having perimedullary drainage, ${ }^{1)}$ is one vascular abnormality reported in patients with neurofibromatosis type 1 (NF-1). ${ }^{1-6)}$ The VAVF with an extracranial vertebral aneurysm (EVAn) in patients with NF-1 has been reported, but is considered to be rare. ${ }^{1-4,6)}$ Furthermore, there is only one reported case of $\mathrm{SAH}$ in a case of VAVF with an EVAn, which accompanied with cervical meningocele. ${ }^{1)}$ We report a case of SAH from VAVF with an EVAn in a case of NF-1 without any other lesions or perimedullary drainage.

\section{Case Report}

A 59-year-old patient was admitted to our hospital. The patient did not have any previous medical

Received December 7, 2017; Accepted January 16, 2018

Copyright $@ 2018$ by The Japan Neurosurgical Society This work is licensed under a Creative Commons AttributionNonCommercial-NoDerivatives International License. history, but there was a family history of NF-1. The patient was in a comatose state. Diffuse skin lesions were observed on the trunk (Fig. 1A). The patient was intubated and sedated. Computed tomography (CT) revealed SAH (Fig. 1B) and acute hydrocephalus. The CT angiography did not show any apparent intracranial aneurysm, but an extracranial aneurysm with a varix was detected in the left vertebral artery (VA) at the level of C4. The varix was located in the epidural space without perimedullary vein drainage. Subarachnoid hemorrhage was also confirmed at the same level of location of the EVAn and/or varix (Figs. 1C and 1D). The EVAn and varix were considered to be the origin of the SAH. Emergent external ventricular drainage was performed for acute hydrocephalus, followed by cerebral angiography, which showed a left VAVF accompanying the EVAn and varix, and the fistula point was located at the level of C4. A drainage route consisting of the epidural and paravertebral veins were clearly seen, but there was no involvement of any retrograde perimedullary veins such as anterior spinal vein or posterior spinal vein (Figs. 2A-2D). The left VA seemed to be sacrificable as the right VA developed well. Parent artery occlusion 

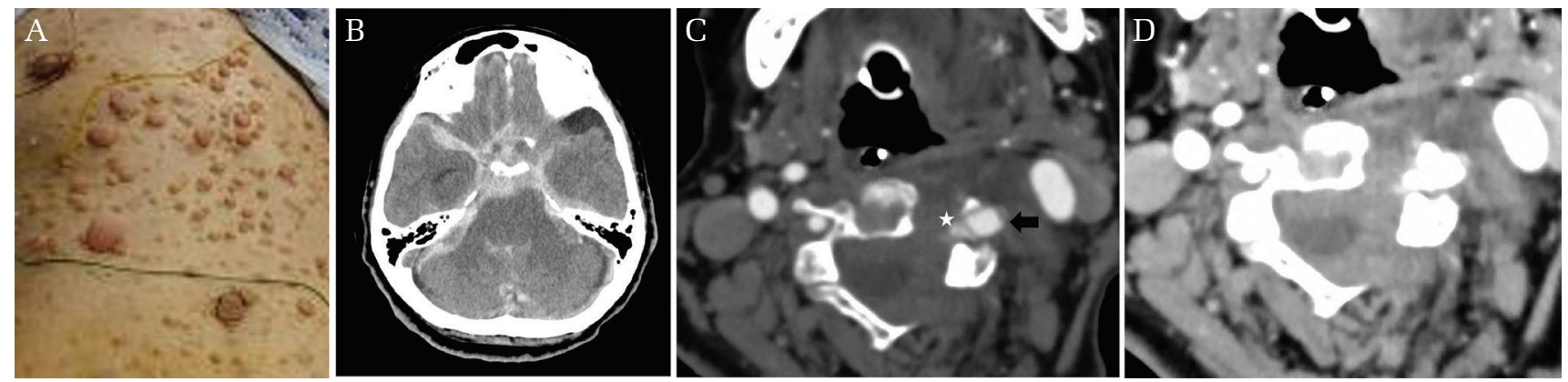

Fig. 1 (A) Subcutaneous neurofibroma and diffuse café-au-lait spot on the trunk. (B) Massive subarachnoid hemorrhage with hematoma in the fourth ventricle. The computed tomography angiography and venography revealing the vertebral aneurysm (black arrow) and the varix (white star) at the level of C4-C5. The vertebral aneurysm and the varix are located epidurally. (C) The left transverse process is invaded by the vertebral aneurysm and the varix. (D) Subarachnoid hemorrhage confirmed around the spinal cord at the level of C4-C5.
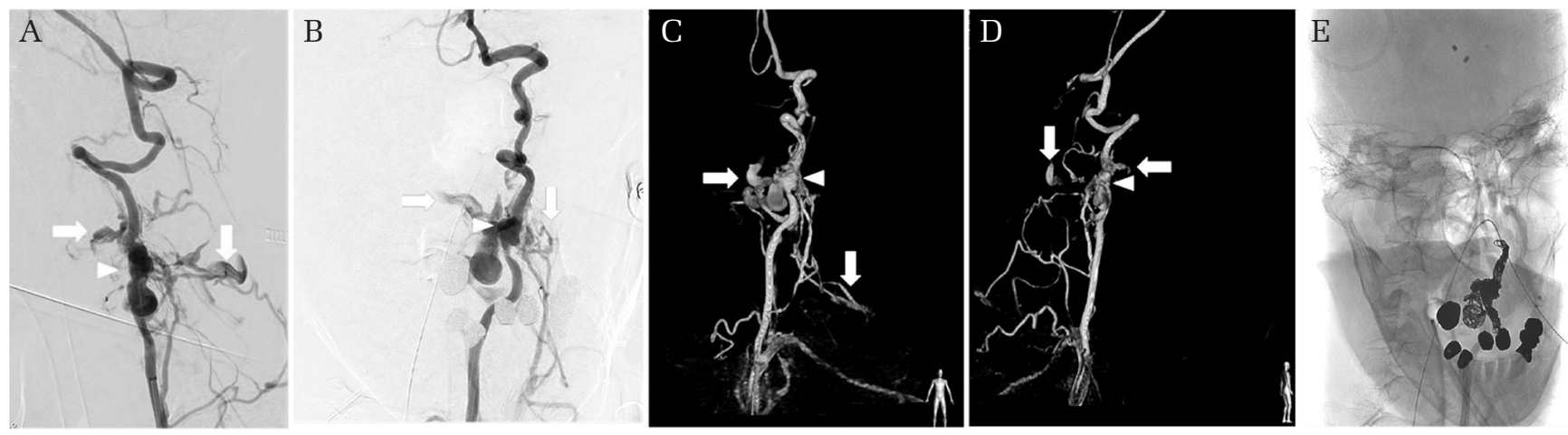

Fig. 2 The cerebral angiography showing a left vertebral arteriovenous fistula (VAVF). The superficial vertebral venous plexus was identified as the drainage route (white arrows). There is no apparent perimedullary drainage route. The extracranial vertebral aneurysm (EVAn) is also demonstrated (arrowhead). (A) Working angle RAO 106, cranial 12, (B) working angle RAO 13, cranial 19. Three-dimensional reconstruction image of the cerebral angiography showing the VAVF. As seen in Figs. $2 \mathrm{~A}$ and $2 \mathrm{~B}$, the superficial vertebral venous plexus are shown as the drainage route (C and D white arrows). The EVAn is indicated (arrowhead). (C) RAO 7, (D) RAO 112. After coil embolization, the VAVF (E) working angle RAO 13, cranial 19.

was performed with endovascular treatment, and following occlusion of the left VA from C3 to C5, the left VAVF with an EVAn and epidural varix resolved (Fig. 2E). There was no apparent supply from the right VA to the left VAVF with an EVAn. After surgical treatment, the patient was referred to a dermatologist for the skin lesions. Histopathological evaluation of the dermal lesions was not performed due to the postoperative state, and we made a clinical diagnosis of NF-1. Tracheostomy was performed 5 days after coil embolization. Rerupture from the left VAVF was not apparently observed with follow-up CT images. The neurological state of the patient did not improve. The patient ended up spending 2 months in our hospital and then was transferred to another hospital. The patient died because of pneumonitis 1 year after the discharge.

\section{Discussion}

The VAVF has been reported as a relatively rare vascular abnormality in patients of NF-1..$^{1-6)}$ Complication in such cases with an EVAn is considered to be a further rarity. ${ }^{1-4,6)}$

Deans et al. speculated two possible mechanisms about the manifestation of VAVF in patients with NF-1: a congenital lesion or a secondary lesion. ${ }^{7}$ Because of our patient is an adult, we considered the VAVF unlikely to be a congenital lesion, and most likely resulting from a VA with a weakened arterial wall related to NF-1. This hypothesized mechanism can be supported by the coexistence of an EVAn and epidural varix.

Clinical symptoms caused by VAVF with EVAn are variable, ${ }^{1-6)}$ but SAH related to VAVF with an 
EVAn in a patient of NF-1 observed on radiology has been reported only in one case. ${ }^{1)}$ In this case, there were limited findings of SAH on MRI, and the final diagnosis was made with a lumbar tap as described by Morvan et al. ${ }^{1)}$ In the same case, a meningocele was located close to a vertebral aneurysm, and the authors hypothesized that SAH was probably caused by rupture ofthe EVAn to the meningocele. ${ }^{1)}$ In our case, no other lesion accompanied the VAVF with a vertebral aneurysm. Our case is considered to be the first case of VAVF with an EVAn causing SAH without any other lesions.

Craniovertebral arteriovenous fistula (AVF) or perimedullary AVF is considered to be a cause of $\mathrm{SAH}$ due to perimedullary drainage. ${ }^{8)}$ The $\mathrm{SAH}$ occurred in our case, however, only the vertebral venous plexus was functioning as a drainage route of the VAVF. Even though the involvement of any retrograde perimedullary veins was not confirmed on cerebral angiography, hemodynamic stress to the epidural varix through the VAVF could result in $\mathrm{SAH}$ in our case. Intracranial venous congestion related to the VAVF also might cause SAH. In addition to hemodynamic mechanism, tissue fragility of the dura related to NF-1 could cause $\mathrm{SAH}$ in our case. The EVAn and epidural varix were located close to the dura mater. Hemorrhage from the epidural varix could have flowed through the dura mater into the subarachnoid space and resulting in SAH. Our speculation on the mechanism of SAH related to rupture of the VAVF with an EVAn and epidural varix seems possible, because the fragility of the dura mater in patients with NF-1 has been described. $\left.{ }^{9}\right)$ As SAH was also confirmed at the level of C4-C5 where the EVAn and epidural varix existed, our speculation seems to be applicable.

The treatment of the VAVF with a vertebral aneurysm by direct surgery or endovascular coil embolization has been reported..$^{1-4,6,10)}$ In a case of Guzel et al., VAVF with a vertebral aneurysm was successfully treated by direct surgery; however, an anterior fixation was needed for postoperative cervical instability. ${ }^{10)}$ As the pathology of VAVF is a shunt between the arteries and the veins, it can be difficult to control intraoperative bleeding if direct surgery is chosen. Endovascular embolization did not contribute to good outcome in our case probably due to preoperative damage related to SAH. However, to avoid intraoperative bleeding and possible additional surgery, endovascular embolization can be better as the treatment for VAVF with a vertebral aneurysm in the case that the VA of the lesion side can be sacrificed.

\section{Conclusion}

We reported a case of NF-1 accompanied with VAVF and EVAn, which was treated with endovascular coil embolization. Possibly due to hemodynamic stress of the VAVF and tissue fragility of the dura related to NF-1, SAH occurred in our case despite the VAVF with an EVAn was lacking of perimedullary drainage.

\section{Acknowledgment}

We thank Paul Williams (Kurashiki Central Hospital) for his extensive proofreading of this article.

\section{Compliance with Ethical Standards and Informed Consent}

The authors obtained informed consent from the patient and her family.

\section{Conflicts of Interest Disclosure}

The authors report no conflict of interest concerning the findings specified in this paper.

\section{References}

1) Morvan T, de Broucker F, de Broucker T: Subarachnoid hemorrhage in neurofibromatosis type 1: case report of extracranial cerebral aneurysm rupture into a meningocele. J Neuroradiol 38: 125-128, 2011

2) Roth TC, Manness WK, Hershey BL, Yazdi J: Complex vertebral arteriovenous fistula and ruptured aneurysm in neurofibromatosis: a therapeutically challenging case. Skull Base Surg 10: 35-41, 2000

3) Uneda A, Suzuki K, Okubo S, Hirashita K, Yunoki M, Yoshino K: Neurofibromatosis type 1-associated extracranial vertebral artery aneurysm complicated by vertebral arteriovenous fistula after rupture: case report and literature review. World Neurosurg 96: 609.e13-609.e18, 2016

4) Higa G, Pacanowski JP, Jeck DT, Goshima KR, León LR: Vertebral artery aneurysms and cervical arteriovenous fistulae in patients with neurofibromatosis 1 . Vascular 18: 166-177, 2010

5) Hauck EF, Nauta HJ: Spontaneous spinal epidural arteriovenous fistulae in neurofibromatosis type-1. Surg Neurol 66: 215-221, 2006

6) Ushikoshi S, Goto K, Uda K, Ogata N, Takeno Y: Vertebral arteriovenous fistula that developed in the same place as a previous ruptured aneurysm: a case report. Surg Neurol 51: 168-173, 1999

7) Deans WR, Bloch S, Leibrock L, Berman BM, Skultety FM: Arteriovenous fistula in patients with neurofibromatosis. Radiology 144: 103-107, 1982 
8) Kinouchi H, Mizoi K, Takahashi A, Nagamine Y, Koshu K, Yoshimoto T: Dural arteriovenous shunts at the craniocervical junction. J Neurosurg 89: 755-761, 1998

9) Schonauer C, Tessitore E, Frascadore L, Parlato C, Moraci A: Lumbosacral dural ectasia in type 1 neurofibromatosis. Report of two cases. J Neurosurg Sci 44: 165-168; discussion 169, 2000

10) Guzel A, Tatli M, Er U, Kazanci A, Ozturk HM, Belen D: Surgical treatment of cervical arteriovenous fistula in a patient with neurofibromatosis type 1 . A case report. Neuroradiol J 20: 566-569, 2007

Address reprint requests to: Yoshinori Maki, MD, Department of Neurosurgery, Kurashiki Central Hospital, 1-1-1 Miwa, Kurashiki, Okayama 710-8602, Japan. e-mail: maki0427@kuhp.kyoto-u.ac.jp 